\title{
SPINOZA ON THE KNOWLEDGE OF GOOD AND EVIL
}

\author{
WILLIAM K. FRANKENA
}

In Book IV Spinoza says a number of things about the knowledge of good and evil that appear to be significant for his argument as a whole, but which are by no means all as clear and distinct as they should be. The purpose of this essay is to examine these and certain related passages in order to say something more about Spinoza's meta-ethics than is said by $C$. D. Broad and others, in the hope that this will be of intrinsic interest to students of Spinoza, of Continental Rationalism, and perhaps even of meta-ethics, besides being of use in understanding and assessing Spinoza's view as a whole. It will therefore deal with those passages only insofar as they throw light on his meta-ethics, i.e. on his views about judgments of value. It will, moreover, be concerned only with the meta-ethics of judgments of good and evil, not with that of judgments of virtue and vice, which may be somewhat different.' To simplify matters I shall frequemly talk only about the knowledge of good (K(i) rather than about the knowledge of good and evil (K(F), assuming that what is said about KC; will also apply, mutatis mutandis, to the knowledge of evil (KE), which is true except for one point to be dealt with separately in Section VII.

There are three main respects in which Spinora's metaethics of good and evil is ambiguous and unclear. (1) He is ostensibly a naturalist in G.L. Moore's sense, or at least a

Spinozats definitions of vintue and vice are a bit different from those of good and evil. I believe, however, that he would say much the same things about the knowledge of virtue and vice that he does about KGE. 
definist, for he explicitly gives definitions of good and evil (somewhat different ones in different places) that play a crucial role in his proofs of some of his own evaluative judgments, as Broad points out and as $I$ assumed in an earlier paper on Spinoza's meta-ethics." This suggests that he would say:

a. that judging $x$ to be good $=$ judging that $x$ has DP (a certain defining property),

b. that knowing $x$ to be good $=$ knowing that $x$ has DP.

However, this is not what he actually says when he tells us what $\mathrm{KG}$ is, as we shall see. What he does say sounds, on the face of it, not only like hedonism, but also more like emotivism than like naturalism. He also says other things that go more naturally with emotivism than with naturalism. (2) Usually, Spinoza's definitions of good and evil are not hedonistic, but, as we shall also see, there is one in which he seems to build hedonism into the very meaning of "good" and "evil". (3) He seems in some places to hold that we judge things to be good because we desire them, not vice versa, and in others that we desire them because we judge them to be good. These three problems will be touched on in due course and other unclarities and problems will turn up as we go along.

One might begin this review of Spinoza's meta-ethics with a discussion of his definitions of good and evil, but I have said something about them in the previous paper referred (o) and wish here to focus on what Spinoza says about KGE, referring $\omega$ his definitions only as they become relevant. I shall therefore proceed by starting with his most important proposition about KG.F, bringing in earlier and later passages that bear on it, and then going on to look at some (but not all) of the other things he says about KGE.

- Sec C.D. Broad, Five Types of Ethical Theory, New York: Harcourt, Brace and Co., 1930, pp. 257, 259; W.K. Frankena, "Spinora's 'New Morality'," in Spinoza, ed. hy E. Freeman and M. Mandelbaum, La Salle, Ill.: Open Court, 1975, pp. 61-84. 
The proposition referred to is P8, IV:

Knowledge of good and evil is nothing but an affect of joy or sorrow insofar as we are conscious of it."

Here we may read "pleasure" for "joy" and "pain" for "sorrow". As was indicated, this proposition is both more emotivistic and more hedonistic, on its face at least, than one would expect, given most of Spinoza's definitions of good. For, given those definitions, one would expect him to say that KG simply is the knowledge that something is useful to us, or contributes to the preservation of our being, or increases our perfection, or is a means by which we may come nearer to the model of human nature we set before us - depending on which definition one picks. Had he said this, and only this, his view would be clearly naturalistic and it would leave open the question whether pleasure is the good. ${ }^{4}$ Actually, however, P8 seems to assert something more like one of the following views:

a. $\mathrm{KG}=$ having joy (or pleasure). about $x$.

b. Judging $x$ to be good $=$ having an emotion of joy

(a) would be gladly agreed to by a hedonist and (b) by an emotivist.

Three questions arise. (1) Just what does P8, IV, say? To answer this we must try to see what Spinoza had in mind, partly by looking at his proof, partly by looking at things he says earlier, and partly by looking at what he goes on to say. (2) How does his proof go, and does it establish what

Here and elsewhere I quote from W.H. White's translation.

- Of course, he would be a naturalist only if the concepts used in his definitions can themselves be analyzed in naturalistic terms. Here I use "naturalist" for anyone who defines ethical concepts wholly in nonnormative terms. I should note, however, that G.F. Moore took Spinoza to be a "metaphysical" definist, not a naturalistic one. I leave open the question whether he is right about this. See Principia Ethica, Cambridge University Press, 1929, pp. 110, 113. The assertion Moore cites as making Spinoza a metaphysical definist is not actually one of Spinoza's definitions proper. 
P8, thus interpreted, asserts? (3) Why does he bring P8 in at all? Why does he not simply say that $\mathrm{KGE}=$ knowing whether things contribute to the preservation of our being (etc.) or not?

Since we must use Spinoza's proof in answering any of these questions, we must have it before us. I shall not quote it, however, but restate it in a series of numbered statements as follows, writing in the definitions and propositions Spinoza refers to:

1. We call a thing good which contributes to the preservation of our being. Defs. 1, IV.

2. The effort by which each thing endeavors to persevere in its own being is nothing but the actual essence of the thing itself. P7, III.

3. Therefore, we call a thing good which increases or helps our power of acting.

4. Joy is the passion by which the mind passes to a greater perfection. Def. of joy, Schol. PII, III.

5. Therefore, we call a thing good in so far as we perceive that it affects us with joy.

6. The mind not only perceives the affections of the body but also the ideas of these affections. P22, II.

7. Therefore, KG is nothing but the idea of joy that necessarily accompanies the affect of joy itself.

8. This idea [of joy] is united to the affect [of joy] in the same way that the mind is united to the body. P21, I1.

9. Therefore, this idea is not really distinct from the affect itself. Schol. P21, 11.

10. An affect is an affection of the body by which its power of acting is increased or diminished, helped or hindered, together with the idea of this affection of the body. Def. 3, III.

11. Therefore, the idea of joy [referred to in 7, 8, and 9] is not really distinct from the idea of the affection of the body, but only conceptually so.

12. Therefore, $\mathrm{KG}$ is nothing but the affect of joy itself in so far as we are conscious of it.

Filled out in this way, the proof gives us much of what we need to answer our questions. 
It is obvious that P8 is making some kind of equivalence or identity claim. Just what is it claiming to be identical with what? And what kind of identity is it claiming to obtain between them?

(a) As was observed, P8 does not say that $\mathrm{KG}=$ knowing that $x$ contributes to the preservation of our being, which is what one would expect a naturalist to say who accepts the definition of good used here by Spinoza. There is no reason to believe that Spinoza would not accept this equation; he would, in fact, be inconsistent if he did not. But this is not the equation he is concerned to assert explicitly. The equation he asserts in 98 is this: $K G=$ having an affect of joy and being conscious of having it. But $K G$ is rather more ambiguous than Spinoza recognizes, and so we are not yet sure just what is being identified with having an affect of joy and being conscious of it (or more simply, with being conscious of having joy). The phrase "the knowledge of good and evil" may refer to any of the following:

(1) Having concepts of goodness and badness,

(2) Being acquainted with goodness and badness,

(3) Having opinion about what is good or evil,

(4) Having true opinion about what is good or evil.

(5) Knowing that something is good or bad.

Prima facie these are distinct, and one may ask which of them Spinoza means to equate with being conscious of having joy. One is tempted to say that (3) and (4) presuppose (1) and that (1) presupposes (2), and Spinoza might agree, though the latter assertion smacks of empiricism rather than rationalism. It may be objected that Spinoza would not himself distinguish (1) and (2) from (3), (4), and (5), and this may be true; he does think that having an idea (image, concept, or percept) entails making a judgment. ${ }^{5}$ It may also be objected that one should not. put (3) and (4) under the heading of knowledge, as I have. But Spinoza does that himself when he speaks of "knowledge of the first kind" and when he says that $\mathrm{KE}$ is

See e.g. Ps. 17, 28, 35, 43, 49, II. 
inadequate knowledge and I am simply following his usage. Thus my question remains. I believe Spinoza would reply that KGE in all five senses is "nothing but" being conscious of having joy or sorrow. His proof makes it clear, however, that he has (3), (4), or (5) primarily in mind, since it centers on what we call or judge to be good. Thus, he means to insist, particularly, that the "knowledge" that $x$ is good (which may be only opinion) = being conscious that $x$ affects one with joy.

(b) As for the nature of the equation or identity claimed in P8, it is clear that it is not conceptual identity. Spinoza is not asserting anything that is true simply by definition, as he would be if he were to say that $K G=$ knowing that $x$ contributes to the preservation of one's being. Rather, the equation asserted in $\mathrm{P8}$ is one that requires a proof using not only definitions, but also some propositions established earlier on the basis of axioms as well as definitions. Spinoza is asserting an identity that is necessarily, not just contingently, true, but not one that is true by definition alone.

We must remember in this connection that Spinoza holds that mind and body have precisely the kind of identity just described. They are the same in substance but differ in attribute or conceptually. In fact, Spinoza believes that there are three things:

(1) an affection of my body by which its power of acting is increased,

(2) an affect of joy in my mind, which is an idea or perception of that affection of my body, and

(3) an idea or perception of that affect of joy in my mind.

He also believes that these three things are substantially the same and differ only conceptually; by P2I, II, (1) is united to (2) and (2) is united to (3) as the mind is united to the body. But, now, in P8, IV, he is asserting that KG is "nothing but" (3) and it is still not clear what kind of identity he means to ascribe to them. If, as I believe, he is not claiming them to be conceptually or definitionally identical, then he must hold that $K G$ is conceptually a fourth thing besides (1), (2), and (3), and that it is "united 
to" (3) and is "nothing but" (3) in the same way in which the mind is "united to" or "nothing but" the body. I do not think Spinoza sees that he must hold this, but it follows from the fact that he defines the good as what is conducive to the preservation of one's being. For, on this definition, knowing the good is strictly identical with knowing what is conducive to the preservation of one's being and can be only synthetically identical with having an affect of joy of which one is conscious. On an older view of mathematics, which Spinoza would have shared, $2+2$ and $2 \times 2$ were synthetically and necessarily equivalent or identical, and it seems to me that in $P 8$ he must be maintaining that $K G$ and (3) are equivalent or identical in a similar way.

Does Spinoza's demonstration, as stated, actually show that the equation or identity asserted in P8 is true? Looking back at his proof as reformulated earlier, I am not sure that it does. In the first place, ( 1 ) is not established by the definition cited, as it is stated by Spinoza. The definition reads, "By good, I understand that which we certainly know is useful to us." 6 But from this, even if we equate being useful with being conducive to our self-preservation (or perfection), it does not follow that we call a thing good which is conducive to our self-preservation (or perfection). To obtain this consequence Spinoza would have had to say, "By good, we understand that which . . .," where the "we" is not just editorial but refers to all of us, and it is doubtful that he thought we all do mean this by good. Secondly, I do not see at all clearly how (2) gets us from (1) to (3) or even just how (5) follows from what precedes. Thirdly, the crucial step is (7), and it is not obvious that (7) follows from (5) and (6), especially since (7) contains a term, KG, which does not appear in (5) or (6). (5) must mean either of the following:

- Def. I, Bk. IV.

7 See e.g. what he says about "good" in Appendix, Bk. I. 
5a. We call $x$ good if we have an affect of joy in connection with it, i.e. an idea or perception of an affection of the body by which its power of acting is increased, or

$5 b$. We call $x$ good if we have an idea or perception of an affect of joy in connection with it, i.e. an idea or perception of an idea or perception of an affection of the body by which ...

But (6)only tells us that, when our body has an affection of this kind, then we have not only an affect of joy but an idea of that affect, and how, given this and either (5a) or (5b) can we conclude that $\mathrm{KG}$ is nothing but this idea? Spinoza must be assuming two further unstated premises:

13. If we call $x$ good insofar as we perceive that it affects us with joy, then calling $x$ good is nothing but perceiving that it affects us with joy.

14. If calling. $x$ good is nothing but perceiving that it affects us with joy, then knowing $x$ to be good is nothing but an idea of joy which necessarily accompanies an affect of joy.

No doubt, one can affirm some kind of equation, if the antecedents of (13) and (14) are true, but there are a number of possibilities here, and it is not clear one can assert the equation in $P 8$.

However this may be, one wonders why Spinoza did not simply argue as follows, if he meant to start from his basic definition of good:

m. $x$ is good $=x$ is conducive to the preservation of one's being. By def.

$\mathrm{n}$. Therefore judging $\mathrm{x}$ is good $=$ judging $\mathrm{x}$ to be conducive to self-preservation.

o. And $\mathrm{KG}=$ knowing that $\mathrm{x}$ is conducive to selfpreservation.

p. $X$ is conducive to one's self-preservation $=x$ increases one's power of acting $=x$ affects one with joy.

q. Therefore judging that $x$ is good $=$ judging that $x$ affects one with joy.

r. And $\mathrm{KG}=$ knowing that $\mathrm{x}$ affects one with joy. 
So stated, his proof would comport with his previous theory and it would establish $\mathrm{P} 8$ if that previous theory is true.

However, the main question for us is not whether Spinoza proves P8 but what he has in mind in asserting it. About this we can become clearer if we consider P8 in another perspective, also provided by Spinoza. I mentioned earlier that it seems to say something like what a hedonist wants to say, viz. that knowing $\mathrm{x}$ to be good $=$ finding it pleasant, being affected by it with pleasure, etc. For Spinoza, however, this is the conclusion of a longish argument beginning with a non-hedonistic definition of good and including a rather different conception of pleasure from that which is usual among hedonists. The good he defines as what is conducive to the preservation of our being, to an increase in our perfection, etc. Joy or pleasure he defines in several related but somewhat different ways:

(a) It is the passion by which the mind passes to a greater perfection.

(b) It is a man's passage from a lesser to a greater perfection.

(c) It is an affection by which the body's power of action is increased.

(d) It is an affection of the body by which its power of action is increased, together with the idea of this affection."

Behind these definitions of pleasure or joy is the thought that what is basic is an affection of the body by which its power of acting is increased or aided, and that pleasure or joy is either the idea (perception) in the mind of that affection of the body by which its power of acting is increased or aided, and that pleasure or joy is either the idea (perception) in the mind of that affection or a combination of that affection with an idea of it (actually, for

* For these definitions see Schol. P I1, III; Schol. P59, IV; Def. III, Bk. III. 
Spinoza, the affection and the idea of it are substantively identical though qualitatively different). This means that, on Spinoza's view, a joy or pleasure is or includes a kind of perception of good, since it is or includes a perception (perhaps confused, but possibly clear and distinct), of an affection of the body in which its power of acting, etc., are increased or helped, i.e. it is a kind of knowledge of good. It is or involves a cognition, however confused, of a certain fact, and is not simply a blind feeling, as emotivists and hedonists usually conceive it to be. This point is behind what Spinoza says in P8, but it is not what he says in P8. In P8 Spinoza identifies the knowledge of good, not with the idea or perception of a modification of the body (the affect of joy), but with the higher level idea or perception of that first level idea or perception. But, of course, if the first level idea (the affect) is a kind of KG, then the second level idea will also be kind of $\mathrm{KG}$. This is part of what P8 asserts, and it does follow from Spinoza's general position. Then, however, he should have said that there are in a sense two kinds of KG: that represented by the affect of joy itself and that represented by the consciousness of that affect; even though these are in some sense really identical for him, they are at least conceptually distinct. $P 8$ does not make this point explicit. Indeed, it is a bit misleading in suggesting that only the higher level idea involves a cognition of good.

However, P8 is not saying only that consciousness of an affect of joy is a kind of $\mathrm{KG}$. It says or seems to say that all $\mathrm{KG}$ is "nothing but" a consciousness of an affect of joy, and this does not follow from the position just sketched. I believe in fact that Spinoza cannot really be holding, as he here seems to, that $P 8$ is true for all kinds of $K G$, and will try to explain why as we review other passages in which he touches on our subject.

Before looking at other passages dealing with $\mathrm{KGE}$, however, let us consider briefly the third question raised earlier about P8, IV, viz. the question why, in the only place in which he says what $\mathrm{KGE}$ is, he gives us $\mathrm{P8}$, instead of saying that $\mathrm{KG}=$ knowing that something contributes to the preservation (or perfection) of our being. As far as I 
can see, Spinoza's reply would simply be, (a) that there is this further equation which can be proved, and (b) that this further equation is important for later parts of his story. This may be so. It remains true, however, that, logically, KG just is basically the knowledge that something is conducive to one's self-preservation or perfection. It is consciousness of joy if an only if it can be shown that there is a sense in which every case of knowing $x$ to be conducive to one's self-preservation or perfection = being conscious of joy in connection with $\mathbf{x}$. But this equation we shall find reason to think Spinoza cannot establish, even on his own terms.

\section{IV}

Let us now consider other passages in the order of their appearance in the Ethics. (1) Then we must begin with an apparent definition of good - the first to appear formulated in the Scholium to P39, III. In P39 itself he says that one who loves another will endeavor to do him good, and in the Scholium he explains that by good he understands "here" every kind of joy and everything that conduces to it, giving as his reason for so understanding it the fact, previously established, that we call a thing good because we desire it and do not desire it because we judge it good. Now, had he used this definition in demonstrating P8, IV, he would have had a much easier time. Why did he not use it? The answer, I think, is that this apparently hedonistic definition is not his most basic one. Most basic is the one used in proving P8, IV; this one is derivative from that one, since it embodies an equation that needs to be proved by the introduction of further premises. In fact, as I see it, this definition in effect presupposes Spinoza's point in P8 and so could not be used in proving it. Perhaps this is why this definition, if it may be called that, appears only in a Scholium, and why he says it indicates what he means by good "here". At any rate, his basic definition is not a hedonistic one.

Even so, there is another point to be noticed for our purposes. On this definition, KG would not necessarily be a 
consciousness of joy; it would be either that or a knowledge that $x$ is conducive to joy, which is not the same thing. There would, in fact, be two kinds of $\mathrm{KG}$, and so P8, IV, though it would be partly true, would not be true without qualification. There is no reason, even on Spinoza's own general theory, for thinking that knowing $x$ to be good as a means is "nothing but" a consciousness of joy, even if knowing $x$ to be good as an end is such a consciousness. Again we find reason to think, on Spinoza's own terms, that P8, although it tells a truth, does not tell the whole truth and nothing but the truth. Even if knowing that $x$ is good as a means to one's end is always accompanied by joy, which is debatable, it does not follow that it is "nothing but" a consciousness of that joy.

It may be objected here that, according to Spinoza's basic official definitions, all judgments of value must be instrumental ones, none of them can be judgments of intrinsic value. In particular, Def. 1, IV, the definition usually used in Spinoza's proofs of P8, etc., says, "By good, I understand that which we certainly know is useful to us." Now it is true that he insists that the terms good and evil "indicate nothing positive in things considered in themselves," being purely relational. If $x$ is good, it must be good to or for someone. Goodness is not an intrinsic property in G. E. Moore's sense for Spinoza; it is not non-relational. But its being relational is compatible with the making of judgments of intrinsic value. Even if " $x$ is good" means " $x$ is desired or enjoyed by $y$ ", it still may be that $y$ desires or enjoys $x$ for its own sake, and not just because of its consequences, i.e. that it has intrinsic value to or for $y$. Nevertheless, it remains a fact that, except for the secondary definition just discussed (which does allow for judgments of intrinsic value), Spinoza does word his definitions in such a way as to seem to equate value with instrumental value. We should not infer, however, that this is his real intention. For one thing, this would be incompatible with the thrust of $P 8$ and of the definition just referred to. For another, as we shall see, Spinoza wants to say later that some things are "directly good" and "indirectly" bad and vice versa. Furthermore, in $\mathrm{P} 28$, to which we will come, 
Spinoza contends that the highest good of the mind is the knowledge of God, using Def. 1, IV, in the proof. Yet he cannot really mean that the knowledge of God is good simply because it is conducive to something else. It is true that, verbally, he would say that it is good because it is conducive to an increase in one's perfection. But his real point is that to be perfect is to have understanding and knowledge of his second and third kinds, not that it is something else to which these are only means. Thus he is asserting, in effect, that such understanding and knowledge are good as ends. In J. S. Mill's words, " $x$ is conducive to perfection" covers three kinds of cases for Spinoza: the case in which $\mathrm{x}$ is simply a means to perfection, e.g. taking medicine or grinding lenses, the case in which $x$ is a part of perfection (or perhaps even the whole of it), e.g. a knowledge of God, and the case in which it is both e.g. a knowledge of the physics of lenses.

(2) In the Scholium to P39, III, Spinoza also makes a very emotivistic sounding statement.

Each person .. a according to his affect judges or estimates what is good and what is evil. . . Thus the covetous man thinks plenty of money to be the best thing and poverty the worst.

He seems to think that this follows from his thesis that we judge a thing to be good because we desire it, not vice versa. Actually, it asserts something broader, viz. that what one judges good or bad is determined by one's affects or by the affect dominant in one at the time. This is not quite to say that I judge $x$ good because $I$ have a desire for it, but, rather, that I do so because I have some affect $x$ bears on, perhaps a desire for $y$, or, to use Spinoza's examples, covetousness, ambition, or envy. The main question, however, is whether Spinoza can say this and also hold that judging $\times$ good $=$ judging it to be conducive to selfperfection. It is compatible with P8, IV; indeed, he formulates this view in connection with the apparently hedonistic definition of good that presupposes P8. But is it compatible with the view that "good" means "conducive to perfection"? I believe it is, if we suppose that for Spinoza 
an affect like ambition or envy can determine, not only what we find joy and sorrow in, but also what we perceive as conducive to our perfection. Since he equates finding joy in a thing with a kind of perception of its conduciveness to one's perfection, he might well think that one's perception of this is affected by one's affects. Then, however, we may ask once more whether all of our judgments of value are wholly determined by our affects in this way, and especially by those that are passions; and the reply must be, it seems to me, (a) that judgments of extrinsic value may be at least partly determined by our knowledge of relevant facts, and (b) that such value judgments as P28, IV, are determined, not so much by our affects, as by our following a certain line of argument (even if our affects determine whether we follow this line of argument or not). Moreover, (c), even if, or insofar as our value judgments are determined by our emotions, they are not necessarily determined by passions, for there are also active emotions.

(3) P58, III, needs mention next. It says that, besides the joys which are passions, there are affects of joy which are related to us insofar as we act, a point which reappears in IV, P52 and the proof of P59. This means, I take it, that there are two kinds of joy, one a passion and the other an active emotion, and, if this is so, then, by $P 8, I V$, there must in some sense be two corresponding and somewhat different kinds of $\mathrm{KG}$. Moreover, by $\mathrm{Pl}$, III, the first of them must be inadequate and the second adequate. Of this more later.

(4) Note should also be taken of the fact that, both in passages already referred to and in some others, Spinoza stresses the relativity of our judgments of good and evil. Thus, in Preface, IV, he writes:

one and the same thing may at the same time be both good and evil or indifferent. Music, for example, is good to a melancholy person, bad to one mourning, while to a deaf man it is neither good nor bad.

Again, however, we must be careful what inference we draw. Spinoza is insisting that value is relational, but he is not a relativist, except perhaps about the value of things 
like music, money, glory, etc. He certainly is not thinking that the value of understanding in general or of the knowledge of God in particular is relative; such things are good in themselves, in the sense earlier explained, for all human beings whether they are melancholy, deaf, or whatever. It is true that, in his proof of P8, IV, Spinoza seems to emphasize the speaker-relativity of judgments of value; he seems there repeatedly to be saying that one calls good that which is or is perceived by him to be conducive to his perfection, enjoyable to him, etc. Back of this way of speaking is Def. 1, IV, quoted earlier. But it is ambiguous. It can mean either that the good is that which one knows is useful to him or that it is what humans know to be useful to everyone, and probably Spinoza intends it to cover both senses. At any rate, in the sequel to the above passage, Spinoza says that by good he understands "in the following pages everything which we are certain is a means by which we may approach nearer and nearer to the model of human nature we set before us" - and what is good in this sense is not relative to the individual, though it is, of course, relative to the species. In this respect, Spinoza is an objectivist about the value judgments he himself makes in the Ethics even though he remains a relationist throughout.

While this is so, however, Spinoza found it necessary to speak in the more speaker-relative way that is also permitted by his definition in order to establish P8, IV. For it would hardly be plausible for him to claim that a knowledge of what is beneficial to everyone can be equated with or derived from a consciousness of one's own joy at something. No doubt this is why he does not use P8 in his proofs of Ps. 27-28, etc., but only when he wishes to prove propositions like Ps. 19, 64, etc. If so, then we also see more clearly why he finds the equation in $\mathrm{P} 8$ interesting and does not stop with the one that follows from Def. 1, IV. However, even if Spinoza had held in an unqualified way that the meaning of a value judgment is wholly speaker-relative, he still would not necessarily be an emotivist. For he might maintain that " $x$ is good" always means "I desire (or take a pro-attitude toward) x." In A.J. 
Ayer's terms he would then be contending that when one says a thing is good one is asserting that one desires or favors it, one is not just expressing one's desire or liking.

(5) Ps. 14-17, IV, make reference to KGE, but we shall consider them only insofar as they bear on our inquiry, not as they related to the topics of human bondage or freedom. The first thing that strikes the eye then is the fact that Spinoza speaks here, not just of KGE, but of "true" KGE, making it clear that he means P8 to be true of such KGE. But now the question arises: Is there false $\mathrm{KGE}$ or is all KGE true? The fact that Spinoza calls it knowledge does not mean he believes it is all true, for not all knowledge of the first kind, as he calls it, is regarded by him as true. On the other hand, in P16 and its proof he talks of KGE and true KGE as it they were interchangeable, and, actually, I believe Spinoza must hold that any idea of joy, however confused, must contain some true knowledge of good (i.e. some true perception of an increase in one's perfection), except where the joy is excessive, as it may be. It is true that in his proof of Pl5 Spinoza says things which imply the view that true KGF can only be adequate knowledge, i.e. knowledge of the second or third kind, but he cannot really be holding this view, for he later contends, as we shall see, that KF is always inadequate knowledge (knowledge of the first kind). In any case, I think he is committee to the position that there are two kinds of $\mathrm{KG}$, one adequate and the other inadequate, and both true, one confusedly and the other clearly and distinctly - of which also more later. It is true that he says falsity consists in the privation of knowledge which inadequate ideas involve, but this is consistent with holding that such ideas also contain truth.

In Ps. 14-15 and their proofs, both of which use P8, Spinoza distinguishes between KGE insofar as it is true and KGE insofar as it is an affect. It has then somehow two aspects. It is tempting to recall Spinoza's distinction be- 
tween an affect of joy and the idea of that affect and to say that it is the latter that is true and the former that is an affect (the two being as identical as those two sides of a coin, the mind and the body, so that in a sense it is the same thing that is both true and an affect). But this will not do if, as Spinoza explicitly holds, it is only the latter that is a cognition of good. And, if we add that the former is also a kind of cognition of good, as I suggested earlier, then it will not do either. One must say, it seems to me, that both of them have both of the aspects in question. In any event, in insisting on the basis of P8 that KGE is an affect and not simply true, Spinoza seems to be implying that it is not just "an idea by which the mind affirms a greater or less power of existence for the body than it possessed before," but something with an affective quality as well.9

(6) This brings us to P19, IV, the proof of which also uses P8. It states that one necessarily desires that which he considers to be good. In fact, Ps. 15-17 already implied that a (true) KG generates desire for the objects involved. This seems to mean that Spinoza thinks that, when this happens, we desire what we desire because we judge or know it to be good, which is not what one would expect an emotivist to hold. However, as was indicated earlier, Spinoza elsewhere is very insistent that

we neither strive for, wish, seek, nor desire anything because we think it to be good, but, on the contrary, we adjudge a thing to be good because we strive for, wish, seek, or desire it."

He also seems to mean this without qualification, i.e. that we never desire a thing because we judge it good but always judge it good because we desire it. This is the sort of thing an emotivist would most naturally say. Also, if it is meant without qualification, it is contradicted by Ps. 14-19, $I V$, if these later propositions must be taken to mean that we sometimes desire a thing because we judge it to be good, as seems to be the case. This raises the third of the

* For the words quoted see Demonst. P 14, IV.

"Schol. P 9, III. 
problems about Spinoza's meta-ethics mentioned in my introduction, besides bearing on the first. Before commenting on it, however, let us consider what Ps. 14-19 say. As I said, they seem to affirm that we sometimes desire a thing because we believe or know it to be good, but this still leaves two possibilities:

(a) that this desire is generated by KG insofar as it is true,

(b) that this desire is generated by $\mathrm{KG}$ only insofar as it is an affect of joy

On the first alternative, the mere fact that we know that $x$ contributes to the preservation of our being generates a desire for $x$; on the second, it does not. What Spinoza says in P14 and in the proof of P19 suggests that he espouses (b), since it involves insisting that, by P8, KG is the affect of joy itself insofar as we are conscious of it; that it is true seems not to play a role. He could, however, agree that (a) is sometimes true, since he thinks of the essence of man as an endeavor to persevere in one's being. "For, given this conatus, one will necessarily desire $x$ if one judges it to be useful in preserving or perfecting one's being. It may also be, of course, that Spinoza would regard the choice between (a) and (b) as academic, because for him a knowledge that $x$ is useful to us and a consciousness of joy about $x$ are two sides of the same coin. But, if this is so, why does he insist in $\mathrm{P} 14$ that no affect can be restrained by the true KGE insofar as it is true, but only insofar as it is an affect?

Perhaps a consideration of the proof of P19 will help us both with this question and with that of reconciling P19 with Schol. P9, III. For us the crucial part goes as follows:

1. $\mathrm{KG}=$ the affect of joy itself insofar as we are conscious of it. $P 8, I V$.

2. We endeavor to bring into existence whatever we imagine conduces to joy. P28, III.

1 P 7, II. 
3. Therefore, one necessarily desires that which he considers to be good.

The clinching point seems to be that considering a thing to be good = imagining it to be conducive to joy $=$ being conscious of it with joy. Now, here again, we may raise our earlier question whether P8 establishes the first of these two equations. Even if it establishes that judging or knowing $\mathbf{x}$ to be good in itself = being conscious of it with joy, it does not thereby establish that judging $x$ to be good as a means $=$ being conscious of it with joy. But, however this may be, we must observe that Spinoza is here in effect asserting only that, if we are conscious of $x$ with joy (= judging or knowing it to be good), then we necessarily desire it. He is not quite saying that we then desire it because we are conscious of it with joy (or because we judge or know it to be good). Certainly he is not claiming that, whenever we desire a thing, we do so because we are conscious of it with joy or because we judge or know it to be good. Still, he does elsewhere seem to hold that we sometimes desire a thing because we judge or know it to be good or because we are conscious of it with joy. ${ }^{12}$ We must simply conclude that Spinoza cannot consistently maintain that we always judge $x$ to be good because we desire it or that we never desire it because we judge it to be good. Contrary to Schol. P9, III, he must be believing that we sometimes desire $x$ because we judge or know it to be good (= being conscious of it with joy), even though we also sometimes judge or know it to be good (and are conscious of it with joy) because we desire it. This more qualified position is compatible with his also holding, as he certainly means to, that we would not judge or know anything to be good, or be conscious of it with joy, if we did not first have a desire to preserve or perfect ourselves. For, even if this is true, it still may be that we may not desire a certain $x$ unless we judge it to be good or are conscious of it with joy - or even that we never desire a particular $x$ unless we so judge or are conscious of it. We may also observe that, while this more qualified view is

12 P 28, III; Ps. 14-17, IV. 
compatible with an emotivism maintaining that when one makes a value judgment one is directly or indirectly expressing one's basic conatus to persevere in one's being, it is also consistent with a naturalism contending that " $x$ is good" means " $x$ is conducive to self-preservation."

(7) Next, we must examine Ps. 27-28, IV. In them Spinoza is not doing meta-ethics; he is making certain value judgments himself, and he is claiming, not only that they are true, but that he can prove them. This means that he believes them to constitute adequate knowledge of the second kind. The two value judgments are:

a. That which conduces to understanding is (certainly) good (and that alone).

b. The highest good of the mind is the knowledge of God.

What interests me now is not the content of these value judgments but their form and the implied claim that they constitute a kind of KG that is adequate or clearly and distinctly true. In form they are general or universal; what is said to be good is not some particular thing but a kind of thing. The question (once more) is whether Spinoza thinks that such general knowledge too is "nothing but" an affect of joy insofar as we are conscious of it. It is hard 10 see how he can believe this, even if he is talking only about knowledge of what is good in itself, and not about knowledge of what is good merely as a means. It is easier to believe that knowing a particular thing to be good in itself is a consciousness of joy in that thing than that knowing a general truth about what is good in itself is a consciousness of joy at a kind of thing. Is knowledge of the sort involved in Ps. $27-28=$ consciousness of joy in getting understanding or a knowledge of God? Is it not rather a matter of grasping the proofs offered by Spinoza? We certainly seem there to be knowing these two truths, not via a consciousness of joy, but via a deductive argument, if we know them at all - a deductive argument, moreover, which contains no mention of any joy that accompanies the getting of understanding or of a knowledge of God, and also no use 
of P8. Even if our coming to know these two propositions about what is good is itself accompanied by a consciousness of joy, it cannot be this joy that constitutes a cognition of the goodness of understanding in general or of a knowledge of God in particular. Again, it appears that P8 cannot plausibly be true of all KG. If our KG in Ps. 27-28 comes to us through its being proved that understanding things and knowing God are profitable to the mind and not through our finding joy in such understanding and knowing, then it will hardly do to contend that all $\mathrm{KG}=$ finding joy in such activities of the mind. Even if such $\mathrm{KG}$ and such joy were somehow ontologically one, as mind and body are, they would not be in the same boat epistemically.

It may be that Spinoza would wish to reply here that there are two ways of knowing that the knowledge of God is good: a discursive way via grasping his proof and a more direct or intuitive way via finding joy in such knowledge. This is what I think he should say, but then again he must distinguish two kinds of $\mathrm{KG}$ and apply $\mathrm{P} 8$ - and perhaps also some of the other things he says about KG - to only one of them.

(8) Ps. 41-48 should be noticed here. In them again Spinoza is making and purporting to prove value judgments like:

(a) Joy is directly good.

(b) Sorrow is directly evil.

(c) Cheerfulness is always good.

(d) Pain may be indirectly good.

(e) Hatred can never be good.

(f) Hope and fear can be good only insofar as they are able to restrain excesses of joy.

Some of these are general judgments of intrinsic value and some general judgments of extrinsic value, and, once more, it seems to me that on Spinoza's own terms judgments of both kinds embody a sort of KG that is not nothing but an affect of joy insofar as we are conscious of it. In particular, I think that knowing certain joys to be excessive and knowing certain pains to be indirectly good cannot be 
equated, respectively, with being conscious of sorrow or joy in experiencing those joys or pains. In any case, we should observe that Spinoza is here distinguishing two cases of $\mathrm{KG}$, viz. knowledge of direct goodness and knowledge of indirect goodness, and must be thinking that knowledge of both sorts may be adequate.

We may now usefully restate one result of our discussions in (1), (7), and (8) as follows Not every piece of KG comes via joy experienced at the time of the knowing or judging on Spinoza's view, though P8, IV, suggests it does. Even if it is accompanied by joy, this will be joy at having that piece of knowledge, i.e. this joy will be a cognition of the goodness of that bit of $\mathrm{KG}$, not a cognition of the goodness of something not going on at the moment. But we do sometimes have knowledge of the value, direct or indirect, of something that is not going on at the time, e.g. when we know that exercise is conducive to health or that knowledge of God is the highest good. It still may be, however, that every joy or consciousness of joy is or includes a judgment of value that is at least partly true.

Also in Ps. 4lff, Spinoza says that joy may be excessive and/or indirectly bad, but maintains that cheerfulness, a certain kind of joy, can never be excessive and so is always good. His argument is that cheerfulness is joy which, insofar as it is related to the body (as, of course, it basically is), consists in the fact that all parts of the body are equally affected, so that the body's power of action is increased or assisted throughout, without any opposing tendency. Therefore it is good both directly and indirectly (or wholly good).

If this is so, then there are two kinds of joy: those that may be excessive and/or indirectly bad and those that can never be excessive or bad. But this seems to imply that there are two corresponding kinds of perception (or knowledge) of good: (a) those consciousnesses of joy that are or may be misleading because the joy is actually excessive or indirectly bad, and (b) those that are always entirely veridical. In the former, as was indicated earlier, 
there is always some truth (for joy is always directly good), but there is or may also be some error; there is error insofar as the outcome of what is reported as good via the feeling of joy is a net decrease in the body's power of action (or in one's perfection.) In the latter there is nothing but truth, though the truth may be confusedly perceived. It may be that this distinction collapses into that already made between joys that are passive and those that are active (and between corresponding kinds of $\mathrm{KG}$ ). It does, if cheerfulness is an active joy, while those that may be excessive are passive ones. It is not clear, however, that $S$ pinoza regards cheerfulness as an active emotion. The Scholium to Pll, III, implies that it is a passion, but a later passage leaves this question open, and the proof of P59, IV, is ambiguous on the point.

\section{VII}

(9) In his Scholium to P62, IV, Spinoza reminds us that our knowledge of the duration of things is very inadequate and largely based on the imagination, so that our judgments about the order of things and the connection of causes are rather imaginary than real. Then he adds that, as a result, the true KGF we have is "only abstract or universal," and that this is why the desire to which it gives rise is so impotent against other desires. Here he seems to be thinking mainly of our knowledge of indirect good and evil, but he must mean what he is saying to apply to that of direct good and evil as well. He also seems to imply that we have no true knowledge of the value of particular things, as I have been assuming we do. I doubt, however, that he can mean this. In fact,. his premises and conclusions here will apply at least as much to our knowledge of the value of particular things as to that of the value of kinds of things. He might even be thinking that our knowledge of particular things is "abstract" too, in the sense of involving inadequate knowledge of their contexts. In any case, he is obviously speaking mainly about such $\mathrm{KGE}$ as is inadequate, again neglecting to mention that there is adequate KGE. Thus, he is not necessarily holding that the latter is "only abstract and universal," or that the desire it generates 
is weak relatively to other desires. Indeed, if $\mathrm{KGE}$ can be knowledge of his third kind, i.e. intuitive knowledge, then such tenets cannot be true of it. It may be, however, that Spinoza is here implicitly denying that $\mathrm{KGE}$ can ever be intuitive in this way - that it is at best knowledge of the second kind. ${ }^{13}$ But, even then, one may ask whether Spinoza intends what he says here to be true of the KG embodied in P28, IV. Though not based on imagination or inadequate knowledge, it is "only abstract and universal" in a way in which knowledge of the third kind is not, and so presumably a desire arising from it would not be as strong as one based on the third kind of knowledge. At the same time, P62 itself seems to imply that such a desire is not so impotent against desires for present things as desires for future ones are.

(10) In P64, IV, Spinoza says that the knowledge of evil is inadequate knowledge. This is the one point, mentioned earlier, on which what he says about KG does not apply to $\mathrm{KE}$ For, as we have seen, $\mathrm{KG}$ is sometimes adequate knowledge of Spinoza's second kind, though he does somewhat fail to emphasize this fact. In his proof of $\mathrm{P} 64$ he uses $P 8$ to show that $K E$ is sorrow insofar as we are conscious of it, and argues that, since sorrow is a passion resting on inadequate ideas, therefore the knowledge of sorrow $(=\mathrm{KE})$ is inadequate. In my opinion, however, even if this conclusion is true for some KF., it cannot be true for all of it. In cases (b) and (e) listed under (5) we have pieces of $\mathrm{KE}$ that can be proved in Spinoza's system and therefore constitute adequate knowledge of the second kind. That the greatest evil of the mind is ignorance of God the correlate of P28, IV) would be another instance of such KF. Fither such $\mathrm{KE}=$ consciousness of sorrow or sorrow does not depend on having inadequate ideas. Surely Spinoza would prefer the first alternative, which again involves qualifying P8, but in either case he must also qualify P64.

(11) In the Corollary to P64 Spinoza adds that it follows the human mind would have no notion of evil if it had

19. On this point see $\mathrm{P} 36, \mathrm{~V}$. 
none but adequate ideas. If I am correct in saying that not all $\mathrm{KE}$ is actually inadequate on his view, then he is mistaken in thinking this follows. Be this as it may, he elaborates his point in an interesting way in P68, IV: ${ }^{14}$

If men were born free, they would form no conception of good and evil so long as they remained free. For then they would have only adequate ideas and hence no concept of evil, and, since good and evil are correlative, no concept of good either - and therefore no KGE whatsoever. Here we may ask just which concepts and which knowledge we would not have if we were fully free. It is clear that we would not have any confused or inadequate ideas or knowledge and hence no KGE involving them, but we might still have KGE consisting of adequate ideas and adequate knowledge, since there may be such KGE. Against the background of Spinoza's system, there seem to be the following relevant concepts we might or might not have if we were fully free:

(a) the idea of an affection of the body in which its power of action is increased, in which it passes to a greater perfection, etc. (= the affect of joy itself).

(b) the higher level idea of that affect of joy itself $(=$ a consciousness of that joy, which is itself a consciousness of an affection of the body).

(c) the concept of passing from a lesser to a greater perfection, etc.

(d) the concept of something's being conducive to a passage from a lesser to a greater perfection, to the preservation of one's being, etc.

Here (d) is the concept equated with the concept of the good in Spinoza's basic definition of the good, while (b) is the idea equated with KG in the derivative equation asserted in P8, IV, but (a) and (c) will also represent KG is of some sort. Now, what we could not have if we were fully free is anything that presupposes our actually having inadequate ideas or actually passing from a lesser to a

"See also his explanation of Def. III in Schol. P 59, III. 
greater perfection, etc., as becomes clear in $\mathbf{P} 17, \mathrm{~V}$, where Spinoza argues that, since God has only adequate ideas and cannot pass either to a greater or to a lesser perfection, He must be free from passions and cannot be affected with any affect of joy or sorrow. In fact, this is not true, if there are such things as active joys and adequate kinds of KG (as we have seen, and will see again, Spinoza really believes there are, but tends to forget about) unless the having of these presupposes the actually having of inadequate ideas, passions, or passages from a lesser to a greater perfection. But this Spinoza never shows and, as was intimated earlier, may entail a more empiricist view than he is ready to espouse. Does Spinoza as a rationalist really want to say that God does not have the concepts involved in (c) and (d)? Even his saying that God can have no affects of joy seems to be inconsistent with P35, V, in which Spinoza says that God delights in His infinite perfection and hence loves Himself with an infinite intellectual love (which itself seems to contradict Cor. P17, V). Remember that love is joy attended by the idea of the object loved as its cause. But if God can know joy at all then by $P \&$ He must have some kind of KG. In any case, we may suppose that He knows such things as P28, IV, and that ignorance of God is evil, by either the second or the third kind of knowledge, and, hence, that He would have both some KG and some KE even if he knew no joy. As far as I can see, all this would be true of the fully free person as well, if there were one (which Spinoza carefully points out to be contrary to actual or even possible fact).

Having said this, it occurs to me that Spinoza may be thinking that God and the fully free person would make no use of any evaluative or normative discourse. Their discourse would be wholly physical, psychological, mathematical, epistemological, or metaphysical, and they would simply act in certain ways. This view is somewhat suggested by what Spinoza says about God and the free or wise man in IV and V, e.g., in P17, V, and elsewhere. It would involve holding, much as Kant does, that evaluative and normative discourse presupposes the presence of contrary passions, 
imperfections, etc., and so would have no use for those in whom these are not present. It also implies, however, that judging $x$ to be good is not simply the same thing as judging it to contribute to the preservation of one's being, as Spinoza's basic definition seems to say it is. For if these two judgments are the same, then there is no reason why a free man could not make them both, and also no reason why he should not use the term "good" in making his judgment, since he could hardly be prohibited from having two ways of saying the same thing, as Spinoza in effect has of asserting P28, IV. Another way of putting this is to say that this interpretation of Spinoza makes him something other than a pure naturalist about good. But to accept this interpretation is to suppose that the fully free person would not know P28, IV, in the form in which Spinoza states it, since he would know only that a knowledge of God is conducive to an increase in one's perfection, and even that, in some sense, he would not understand any of Spinoza's talk about good and evil in Books IV and $V$. He would have general understanding and a knowledge of God, but he would not know that these are good or that the opposite states (which he surely can conceive of) would be bad. Supposing this does not seem at all plausible, especially if " $\mathrm{x}$ is good" means " $\mathrm{x}$ is conducive to perfection," as Spinoza says it does.

As for the question which of the ideas listed in (a)-(d) above the fully free man would have - Spinoza would apparently say that he would have none of the four kinds of ideas, but, if I am right, he might at least have some of each kind.

\section{VIII}

In part, our results may be summarized by noting that Spinoza explicitly or implicitly recognizes several different ways in which KG (or KGE?) may be divided into two kinds. In the order of their appearance in our discussion these are:

(a) the distinction between the $\mathrm{KG}$ that $=$ knowing what 
is conducive to self-preservation or perfection and the $\mathrm{KG}$ that = having an affect of joy and being conscious of it;

(b) the distinction between the latter kind of $K G$ and the kind of $\mathrm{KG}$ that simply = having an affect of joy [these are substantially identical but conceptually distinct];

(c) the distinction between knowing what is directly or in itself good and knowing what is indirectly or extrinsically good;

(d) the distinction between the $\mathrm{KG}$ (and $\mathrm{KE}$, if $\mathrm{I}$ am right) that is adequate and the KGE that is inadequate;

(e) the distinction, under each of the kinds in (b), between the KG that = having a passive emotion of joy and being conscious of it and that which $=$ having an active emotion of joy and being conscious of it [this distinction may coincide with that in (c)];

(f) the distinction between the KG that is particular, i.e. knowledge that a certain thing is good, and the KG that is general;

(g) the distinction between the $\mathrm{KG}$, that $=$ a consciousness of excessive joy and $\mathrm{KC}$, of the kind involved in cheerfulness [This distinction may coincide with that in (e)].15

Besides distinguishing these, in most cases more explicitly than Spinoza does, I have argued that they cannot all be equated with having an affect of joy and being conscious of it, or, in other words, that some of them are not only conceptually but also more substantially distinct. In particular, I think this is true of the first kinds mentioned in (a) and (d) and the second kinds memtoned in (c), (d), and (f). In short, the equation asserted in P8, IV, is not the whole truth. It also is not Spinora's most basic equation involving KGE, but a derivative one. The basic equation is that KGE. $=$ knowing what is and what is not conducive [in the broad sense indicated in (1) in Section IV above] in selfperfection, etc., which holds for all the kinds of KGE distinguished. The main point left of $P 8$ is the assertion

1. Perhaps one should add (h) the distinction between the KG; that = judging or calling a thing good and the $\mathrm{KG}$ that $=$ knowing that a thing is good. 
that every affect of joy and sorrow and every idea of such an affect is a kind of KGE as defined by Spinora's basic equation and always contains. some truth, even when it is partly mistaken, as it sometimes is. This point by itself separates Spinoza from the hedonist and the emotivist, but this is done even more by the fact that Spinoza really holds, though he seems not to, that there are kinds of KGE which are not reducible to consciousnesses or expressions of joy and sorrow. As Broad puts it, pleasure (joy) is for Spinoza not the ratio essendi of the good, as it is for the hedonist, and in a way for the emotivist, but the ratio cognoscendi. ${ }^{16}$ The ratio essendi of the good is conduciveness to selfperfection, i.e. to knowledge and understanding.

For the rest, we may summarize by referring to the three problems about Spinoza's meta-ethics listed in the incroduction. About the third I have said what I have to say in (2) and (4) in Section IV and (6) in Section V; we saw that there is a consistent position behind the apparently conflicting things Spinoza says in the relevant passages, but that, to hold it, he must modify his claim about the priority of desiring $x$ to judging it good.

'The second problem, already touched on in this summary, was dealt with in Section III and under (I) in IV. In spite of one apparent definition that seems to do so, Spinora does not make hedonism true by definition, his basic definition being nom-hedonistic. He does not proceed from a hedonistic defintion plus axioms and previous theorems. It is true that he could take his non-hedonistic definition of good as basic and yet equate pleasure (joy) and the good at a second or third remove, as he seems implicitly to do in P8. Really, however, even at second or third remove, he equates the good, not with pleasure, but with knowledge or understanding. He agrees with the hedonist that $\mathrm{KG}=$ knowledge of pleasure and of what is conducive to pleasure, but for him this does not mean that the good = pleasure; it means only that all consciousness of joy is a cognition of good and that all cognition of good is a

16. Op. cit., p. 52. 
consciousness of joy - and we have found that he cannot really sustain the latter of these two claims.

As for the first problem - we have seen that P8, IV, does not commit Spinoza to emotivism. For him P8 is just a derivative equation that looks like something an emotivist would say but is not, for behind it is the view that an affect is a kind of cognition, confused or not, of a state of the body. It is true that Spinoza says emphatically that we judge a thing good because we desire it, not vice versa. But (a) this assertion must be qualified, since he also maintains the reverse, and (b) this dictum is compatible with his being a naturalist. Given his view that a person essentially is a conatus (endeavor) for perfection, Spinoza could hold either that a value judgment is an expression of this conatus on its finding that something is conducive to perfection or that it is simply an assertion to this conatus that something is conducive to perfection. In my previous paper I suggested that a Spinozist might choose the first alternative and be an emotivist, but Spinoza himself chose the latter and so is a naturalist. He does sometimes, however, say things that are, verbally at least, compatible with either alternative. He also allows, as we saw in (5) of Section $V$, that a piece of $\mathrm{KG}$ has a affective quality and is not just true (or false), but, if I am right in what I said at the end of (8), this may mean only that a knowledge of something's being conducive to one's perfection is accompanied by joy.

We also saw in (11), Section VII, that God and the fully free person are, on Spinoza's own premises, not so axiologically blind as he represents them as being. But, like our other findings, this only shows that all good things are as difficult as they are rare.

The University of Michigan

Ann Arbor, Michigan 48104

USA 